\title{
Virtual Flauta Doce: projetos de extensão integrados com atividades não presenciais
}

\author{
Isamara Alves Carvalho \\ Universidade Federal de São Carlos \\ isamara@ufscar.br \\ Patricia Michelini Aguilar \\ Universidade Federal do Rio de Janeiro \\ patriciamichelini@musica.ufrj.br \\ David Castelo \\ Universidade Federal de Goiás \\ david_castelo@ufg.br
}

Resumo: O confinamento domiciliar provocado por medidas de controle da transmissão do COVID-19 levou três professores de flauta doce de três universidades federais brasileiras a se unirem num grande projeto de transição para um futuro próximo. Superado o período de angústia, desabafo e compartilhamento de impressões de projetos possíveis, cada um propôs uma abordagem para ser conduzida em plataformas virtuais e respeitando as especificidades dos perfis de pesquisa, extensão e ensino de cada um em suas respectivas universidades. Surgiram, desta forma, os projetos Tocar Junto Virtual - Flauta Doce, Flauta Doce em Sistema e Vida na Flauta. Neste artigo, são apresentados os relatos dos coordenadores destes projetos.

Palavras-chave: flauta doce, cursos de extensão, plataformas virtuais.

\section{Virtual Flauta Doce: integrated extension projects mediated by non- classroom activities}

\begin{abstract}
The lockdown imposed by the COVID-19 protective measures led three recorder teachers from three Brazilian federal universities to come together in one major educational project for a near future. Overcoming a period of anguish, outburst and sharing impressions about possible ways to be pursued on virtual platforms each one proposed a specific approach. It was taken in to account the research and teaching profiles of each teacher in their own university. The present experience report provides an overview about the projects "Tocar Junto Virtual - Flauta Doce", "Flauta Doce em Sistema" e "Vida na Flauta".
\end{abstract}

Keywords: Recorder, Extension courses, Virtual platforms. 


\section{Introdução}

O surpreendente contexto provocado pela pandemia da COVID-19 trouxe, entre as medidas de contenção da disseminação do vírus, a suspensão das atividades acadêmicas presenciais, à exemplo daquela observada nas instituições federais de ensino superior, a partir do mês de março de 2020. O semestre letivo foi interrompido ainda em suas primeiras semanas e, uma vez que todo o planejamento pedagógico havia sido pensado tendo como eixo o ensino presencial, não nos encontrávamos preparados para uma migração imediata para o ensino remoto. Ainda que não houvesse uma perspectiva concreta a respeito do tempo que efetivamente duraria a quarentena, o rápido aumento do número de infectados e vítimas fatais do novo Coronavírus já deixava claro que estávamos lidando com o problema de longo prazo, e que necessitaríamos buscar alternativas para o trabalho universitário.

A interrupção bastante abrupta das atividades presenciais desenvolvidas no cotidiano universitário nos deixou inicialmente sem ação, sem uma saída segura e que contemplasse a diversidade de perfis socioeconômicos, tecnológicos e de aprendizagem dos nossos estudantes, das nossas condições de formação, bem como das estruturas de espaço e condições tecnológicas de nossas casas. Foi necessário, portanto, um período para entender o que estava ocorrendo, analisar, planejar e propor alternativas.

$\mathrm{Na}$ Universidade Federal de Goiás (UFG), as aulas foram inicialmente suspensas a partir do dia 16 de março de 2020, pelo prazo de quinze dias. Nesse momento, a reitoria determinava que as disciplinas presenciais não poderiam ser transformadas em $\mathrm{EaD}$, tanto na graduação quanto na pós-graduação; e sugeria que o contato virtual com os alunos era bem-vindo para sugestão de leituras e atividades de estudo, mas que não poderia contar como aula. A suspensão por tempo indeterminado do calendário acadêmico foi determinada no dia 27 de março, por meio da Resolução CONSUNI n 18/2020. Gradativamente, a partir das discussões dos Grupos de Trabalho (GTs) constituídos, a UFG normatizou a volta de suas atividades acadêmicas.

Situação similar ocorreu na Universidade Federal do Rio de Janeiro (UFRJ). Após um período de apuração dos recursos técnicos de que docentes e discentes dispunham, em que atividades realizadas virtualmente eram incentivadas pela reitoria, porém não obrigatórias, somente no mês de junho foi instituído, por meio das Resoluções 03/2020 e 
04/2020 do Conselho de Graduação, o Período Letivo Excepcional (PLE), autorizando o ensino remoto, ainda que com a adoção de algumas condições especiais.

Na Universidade Federal de São Carlos (UFSCar), a partir da Resolução n ${ }^{\circ} 320$ do Conselho de Graduação, foi instituído o Calendário Suplementar que perdurou entre 05 de maio e 26 de junho de 2020 exclusivamente para oferta, por meios digitais, de Atividades Curriculares de Integração Ensino, Pesquisa e Extensão (ACIEPEs) e disciplinas com caráter de Trabalho de Conclusão de Curso (TCC). Disciplinas obrigatórias e optativas das matrizes curriculares de todos os cursos de graduação da UFSCar ficaram suspensas desde a publicação da Resolução $n^{\circ} 319$ do Conselho de Graduação, datada de 27 de março de 2020.

Nesse período, éramos três colegas docentes em IFES: Isamara Alves Carvalho, professora do Departamento de Artes e Comunicação da Universidade Federal de São Carlos (DAC-UFSCar); Patricia Michelini Aguilar, professora da Escola de Música da Universidade Federal do Rio de Janeiro (EM-UFRJ); e David Castelo, professor da Escola de Música e Artes Cênicas da Universidade Federal de Goiás (EMAC-UFG); que compartilhavam privadamente (por meio do Whatsapp) preocupações com as questões oriundas da pandemia do Coronavírus e seus desdobramentos sanitários, sociais e pedagógicos, no exercício de nossas práticas profissionais. Nos perguntávamos com muita frequência e angústia: Até quando? Como ficarão nossos estudantes e nossas estudantes? Será que teriam acesso a computadores, tablets e conexão de qualidade? Poderíamos ou deveríamos aproveitar as aprendizagens da oferta de disciplinas em cursos na modalidade de Educação à Distância que nossas instituições agregavam considerável experiência? Foram estas e tantas outras perguntas sem respostas precisas naquele momento.

Em consonância com a opção cautelosa de nossas instituições definimos que faríamos a oferta concomitante de três projetos de extensão, respectivamente "Tocar Junto Virtual - Flauta Doce", coordenado pela professora Isamara Alves Carvalho da UFSCar; "Flauta Doce em Sistema", coordenado pela professora Patricia Michelini Aguilar da UFRJ; e "Vida na Flauta", coordenado pelo professor David Castelo da UFG. Cada um de nós planejou uma proposta considerando a própria prática com as 
Tecnologias Digitais de Informação e Comunicação, os interesses de pesquisa e de prática de ensino e performance com a Flauta Doce.

Os produtos resultantes destas interações, "temporariamente definitivos e definitivamente temporários", nas palavras de Nunes (2018, p. 6), foram de extrema importância para estudantes, professores e flautistas carentes de direção, formação e empatia.

A seguir, seguem os relatos de cada um dos projetos feitos por seus coordenadores.

\section{"Tocar Junto Virtual - Flauta Doce" - Profa. Isamara Alves Carvalho (UFSCar)}

Na pesquisa desenvolvida na minha tese de doutorado com o título "Potencialidades de limites de uma disciplina no curso de Educação Musical a distância na UFSCar”, o “estar junto virtual" de Valente (2003) foi um dos principais conceitos referenciados para esclarecer que distância na $\mathrm{EaD}$ não tem relação alguma com estudo solitário ou sem interação. O "estar junto virtual" do autor traz o cuidado com as diversas formas de acompanhamento e interação com os participantes em ambientes virtuais de aprendizagem (AVA). A constância nas devolutivas e esclarecimentos de dúvidas, a variedade de propostas com focos no processo vivenciado e não exclusivamente no produto final elaborado, o uso de comunicação que aproxima, que respeita cada um e cada uma que ali esteja são alguns elementos que podem caracterizar o "estar junto virtual".

Neste sentido surgiu o Projeto de Extensão "Tocar Junto Virtual - Flauta Doce", ofertado entre 04 de maio e 26 de junho de 2020 e tendo o ambiente virtual de aprendizagem moodle como principal software de interação e os aplicativos Facebook e Whatsapp como meios complementares para isso. Além dos colegas David Castelo (UFG) e Patricia Michelini Aguilar (UFRJ), participaram da equipe de implementação do curso a flautista doce Marta Roca (Fundação das Artes de São Caetano do Sul - FASCS) e a servidora técnica de laboratório Josiane Fernanda Covre (UFSCar).

Objetivos esperados:

1. Propiciar espaço e tempo virtual para que pessoas interessadas pudessem continuar praticando o repertório de estudo de flauta doce; 
2. Criar oportunidade de experimentação de recursos tecnológicos para que a prática de tocar junto fosse mantida;

3. Analisar as potencialidades e possíveis dificuldades encontradas e discutidas mediante literatura especializada e relatos dos participantes;

4. Estudar a produção científica sobre ensino de música por meio de recursos tecnológicos;

5. Propiciar condições para que os participantes se capacitassem a fazer práticas similares com seus atuais ou futuros alunos.

No primeiro momento do curso procurou-se entender os perfis dos e das participantes quanto ao repertório que costumavam tocar na flauta doce e qual a localidade de cada um e cada uma naquele momento. A seguir, deixamos parte das orientações do enunciado do Fórum Cartão de Visitas no qual todos e todas deveriam ensaiar e registrar um vídeo solo: “(...) resgatem no material de vocês uma melodia que vocês toquem com tranquilidade (...) e façam o registro em vídeo para que possamos nos conhecer um pouco. Para isso solicitamos que falem, antes de iniciarem a parte musical, o nome, a cidade de origem, a instituição de origem e os critérios da peça escolhida". Após 21 dias de interação encerrou-se o fórum com 149 mensagens e 27 cartões de visitas.

A próxima etapa, depois de todos e todas se apresentarem, foi organizar as duplas para ensaio e gravação dos primeiros duetos com flauta doce. No enunciado deste novo tópico de fórum foi estimulado que cada um e cada uma se desafiasse a tocar em várias duplas e com quem não tinha experiência prévia para que pudesse aumentar a rede contatos da área. Totalizou-se 52 mensagens, 23 duplas e, consequentemente, 23 vídeos foram publicados no AVA do curso.

Ocorreu um fato bastante interessante neste período dos ensaios para registro dos vídeos com duetos. A interação das duplas no moodle foi silenciada. O aplicativo escolhido e, muito provavelmente, que demonstrou melhor eficiência para trocas de arquivos de vídeo foi o Whatsapp. Porém os professores da equipe não participaram dos ensaios. Numa próxima oferta, acredita-se que o uso deste meio deve ser considerado desde o princípio como possibilidade de uso pedagógico também. Com o objetivo de deixar algumas orientações claras para todos e todas antes da publicação final, foi 
disponibilizado uma videoaula contemplando combinados necessários sobre afinação, andamento, articulações, frases, entradas, cortes e a cena (cores e tons que seriam vistos).

Foi possível observar no primeiro programa de peças escolhidas pelas duplas a presença significativa de duetos de compositores brasileiros, entre eles Sérgio de Oliveira Vasconcellos Corrêa, Osvaldo Lacerda, Dorival Caymmi, Alceu Valença, Fernando Lemos, seguidos de duetos presentes em métodos usados com frequência nos cursos de flauta doce e alguns movimentos de sonatas do período barroco.

Neste momento tínhamos um outro dado resultante do primeiro mapeamento de perfis realizado no início do curso. Formamos um grupo de flautistas doces com grande diversidade de dispositivos móveis e habilidades no uso de softwares de edição para compor os chamados vídeos em formato de mosaico. Foi necessário criar estratégias de gravação e edição de vídeos a partir de computadores, tablets e celulares com sistema operacional Windows e IOS. Entendemos que deveríamos valorizar as aprendizagens prévias dos participantes e neste caminho solicitamos a elaboração de vídeos tutoriais para que pudessem auxiliar uns aos outros e umas às outras. $\mathrm{O}$ tópico para esta finalidade recebeu 4 vídeos tutoriais para 3 aplicativos distintos (IMOVIE, FILMORA, ADOBE PREMIERE) e comentários avaliativos para sete aplicativos de vídeos voltados para celulares (VIVACUT, INSHOT, MESCLARVIDEOS, VIDEOMARGER, FILMORAGO e VLOGIT).

Foram abertos dois tópicos no novo fórum da última fase do curso para organizar os trios e quartetos, bem como para ensaiar e publicar os respectivos vídeos. O resultado apresentado contou com 13 vídeos, sendo 7 quartetos e 6 trios. O repertório contemplado desta vez trouxe majoritariamente arranjos de peças populares e movimentos de sonatas do período barroco, além de peças de métodos usados com frequência nos diversos cursos de flauta doce.

Avaliamos que múltiplas aprendizagens foram oportunizadas aos envolvidos no projeto "Tocar Junto Virtual - Flauta Doce". Tocar junto requer, sabemos, muitas habilidades e competências musicais e de interação social. "Tocar junto virtual" agregou às aprendizagens anteriores outras tantas habilidades, a saber: 
- de registrar com o melhor som e imagens possíveis nos limites permitidos pelos dispositivos e softwares que cada um e cada uma possuía no momento do curso;

- de organizar a agenda de ensaios com tempo suficiente para que o editor responsável pelo vídeo final pudesse trabalhar com calma na junção e equalização das vozes, principalmente pela característica de diversidade de dispositivos e softwares;

- de usar aplicativos de interação social para combinados sobre os aspectos musicais a serem considerados nas gravações (afinação, andamento, fraseado, articulações, entradas, cortes e cenários) e para o compartilhamento de arquivos de áudio e de vídeo;

- de usar aplicativos para sincronização e equalização de dois ou mais vídeos;

- de planejar e acompanhar cada uma das etapas do Tocar Junto Virtual tentando antecipar a produção de videoaulas, pois isso requer organização de agenda e domínio de um conjunto de habilidades tecnológicas.

Dentre os objetivos iniciais do projeto não foi possível contemplar o estudo da literatura sobre o ensino de música por meio de tecnologias musicais e seu contraponto com as impressões dos participantes a partir das vivências realizadas no "Tocar Junto Virtual - Flauta Doce", além do Recital público em Redes Sociais. Podemos afirmar que outros módulos deste curso devem ser planejados, porém com adequação de objetivos e conteúdo ou ampliação do cronograma.

Apesar de todas as dificuldades do entorno, provocadas principalmente pela Pandemia do Coronavírus, conseguimos manter a prática de grupos musicais com flauta doce, demarcando envolvimento, criação, superação de dificuldades e prazer para os envolvidos.

\section{"Flauta Doce em Sistema" - Profa. Patricia Michelini Aguilar (UFRJ)}

O projeto de extensão "Flauta Doce em Sistema" foi caracterizado como uma série de encontros remotos semanais, realizados via Google Meet, com o objetivo de apresentar e discutir metodologias e propostas pedagógicas que fazem uso da flauta doce, tanto para 
o ensino deste instrumento quanto como suporte para o ensino de música. O nome faz referência aos sistemas de ensino adotados nas metodologias estudadas e também à natureza da ação, integralmente realizada de maneira remota.

Em complemento aos encontros, o projeto contou com uma Sala de Aula Google para avisos e comunicações, integração entre os alunos e para disponibilizar materiais diversos, tais como os vídeos dos encontros para acesso assíncrono, biblioteca com artigos, textos e livros indicados pelas palestrantes, materiais pedagógicos e lista de presença. A ação contou com 195 inscrições; destes, 143 foram participantes efetivos e observamos uma média de 100 participantes por encontro. Este público se caracterizou por estudantes de Licenciatura em Música, professores vinculados à Educação Básica, professores de flauta doce e demais interessados no uso pedagógico do instrumento.

O primeiro módulo foi realizado no período de 18/06 a 06/08/20, compreendendo 8 encontros de 120 minutos. Tive o apoio imprescindível de dois monitores: Anderson Tiago Rodrigues, meu orientando no Programa de Mestrado Profissional da UFRJ e Luiza Mesquita, aluna do curso de Licenciatura em Música e monitora da Oficina InstrumentalFlauta Doce I. Ambos foram de especial valia na organização dos materiais disponibilizados na Sala de Aula, divulgação em redes sociais ${ }^{1}$, bem como na interação com os participantes.

A seguir, relaciono a lista das palestrantes, suas instituições de vínculo profissional e o tema abordado por cada uma delas: Patricia Michelini (UFRJ): Sobre métodos e metodologias para flauta doce; Luciana Nagumo (EMJ): A flauta doce no curso de Educação Musical da Escola de Música de Jundiaí; Tereza Castro (UFOP): A busca de uma coerência científica para entender ações musicalizadoras com a flauta doce em sala de aula; Melita Bona (FURB): Carl Orff e a flauta doce; Cristal Velloso (Yamaha Musical do Brasil); Sopro Novo: aulas coletivas de iniciação musical através da flauta doce; Daniele Cruz Barros (UFPE) e Laurence Pottier (Conservatoire Nadia et Lili Boulanger/Paris): A concepção dos métodos para flauta doce de Laurence Pottier e suas traduções para o português; Luciana Castillo e Shinobu Saito (ambas do Centro Suzuki de Campinas): Ensino de flauta doce através da Filosofia Suzuki; Lisbeth Soares (FASCS): Pedagogias musicais abertas: implicações para a ação docente.

1 Página no Facebook: https://www.facebook.com/FlautaDoceEmSistema. 
O projeto "Flauta Doce em Sistema" apresentou significativa capilaridade em todo o território nacional, contando com participantes do Distrito Federal e de 19 estados, a saber: Amazonas, Pará, Rio de Janeiro, São Paulo, Minas Gerais, Paraná, Santa Catarina, Rio Grande do Sul, Mato Grosso, Mato Grosso do Sul, Goiás, Rio Grande do Norte, Paraíba, Pernambuco, Sergipe, Bahia, Maranhão, Piauí e Ceará.

Ao final do projeto, foi disponibilizado um formulário de avaliação com questões sobre as ferramentas virtuais adotadas e sobre o conteúdo do projeto, além de espaço para sugestões e comentários gerais. Os depoimentos que destaco abaixo foram retirados destes formulários; os autores estão identificados apenas pelas iniciais de seus nomes por questões de privacidade.

L. C. notou a tendência recente de reduzirmos as opções de propostas pedagógicas com flauta doce àquelas divulgadas nas redes sociais pelos profissionais que as adotam, desconsiderando a diversidade de trabalhos desenvolvidos no Brasil. Nesse sentido, reconheceu a relevância do projeto ao contribuir para a disseminação de parte destes trabalhos e para a integração dos profissionais responsáveis:

Esse espaço de troca e de conhecer diferentes trabalhos no Brasil permite ter um panorama maior do que aparece em redes sociais. Sem conhecer os outros profissionais e seus trabalhos, o diálogo fica difícil de acontecer! Precisamos promover mais espaços de encontro como esse!

Outros participantes relataram a falta de conhecimento em algumas propostas apresentadas e a oportunidade de se aprofundar em outras conhecidas, como C.G.C.M:

Quando realizei a inscrição confesso que não tinha a real ideia do quanto de conhecimento essas semanas trariam (...). Foi muito bom também, conhecer propostas pedagógicas que não conhecia e me aprofundar em outras que já conhecia.

A diversidade de propostas foi destacada por diversos participantes, sendo que vários consideraram que as apresentações serviram como inspiração e complemento às suas práticas pedagógicas:

Nunca participei de uma formação com tamanha abrangência. Ouvi diversas fontes, não apenas uma. Conheci pessoas com diversas formações e diversas formas de ensinar, refleti sobre a minha forma de ensinar ponderando o que devo manter e o que posso aperfeiçoar (...). Acredito que continuarei adotando a minha apostila (...), porém com o enxerto de novas ideias dos métodos apontados no Flauta Doce em Sistema (I.P.O.).

Muito conhecimento adquirido, poder conhecer diversas metodologias abriu um leque de possibilidades para solucionar diferentes problemas na prática musical (M.F.F.S.). 
Saio desse projeto com muita informação, referências e reflexões relevantes sobre a prática e o ensino/aprendizagem da flauta doce (N.D.)!

Foi particularmente gratificante constatar que vários participantes notaram o ambiente acolhedor e respeitoso que foi construído ao longo do projeto:

Senti respeito e cuidado com cada palestrante e metodologia (L.A.S.S).

O respeito pela experiência de cada um se mostrou também em não deixar nenhum material ou bibliografia como "óbvio". Ou seja, não houve momento algum onde se assumiu que qualquer um "deveria" conhecer tal o qual referência. Muito pelo contrário, o que ia sendo mencionado era colocado no Classroom ou no chat para convidar às pessoas conhecer (L.C.).

Por fim, o projeto foi percebido como um troca de experiências entre as convidadas e os participantes, valorizando os saberes de cada um e cada uma com acolhimento e empatia:

\begin{abstract}
Cada história (profissional e de vida) tão linda quanto a outra - isso nos sensibiliza, motiva e impulsiona a continuar e querer estar em contato contribuindo para mais humanidade, arte e sentimento no nosso viver coletivo (H.C.N.).

Em tempos tão difíceis que estamos vivendo, participar deste projeto foi um alento para a alma (K.M.C.C.).
\end{abstract}

O módulo 2 de "Flauta Doce em Sistema" está previsto para os meses de janeiro a março de 2021.

\title{
Projeto "Vida na Flauta" - Prof. David Castelo (UFG)
}

Passado o período de perplexidade e intensas reflexões estimuladas pela leitura de Gohn (2011), iniciei a elaboração do projeto "Vida na Flauta". Entre as preocupações que tive no começo do período de isolamento social estavam, por um lado, a de buscar meios para manter o sentimento de vínculo dos alunos com a UFG e, por outro lado, a necessidade de aproximar ainda mais a comunidade em geral à universidade. Os projetos de extensão são o mecanismo tradicionalmente utilizado para esta finalidade. A proibição de encontros presenciais tornou compulsória a utilização de plataformas virtuais para implementação dos referidos projetos. Essa conjunção de fatores passou a significar uma oportunidade de ampliação tanto do público-alvo quanto do número e origem dos palestrantes convidados para o projeto "Vida na Flauta".

Sob o ponto de vista formal, o "Vida na Flauta" guarda semelhanças com o "Flauta Doce em Sistema", projeto coordenado pela profa. Patricia Michelini Aguilar 
(EM/UFRJ): ambos foram viabilizados por meio da plataforma Google Meet, com frequência semanal e tempo de reuniões de aproximadamente 1 hora e 45 minutos. Os encontros do "Vida na flauta" foram realizados sempre às terças-feiras, das 14:00h às $15: 45 \mathrm{~h}$.

Há, contudo, uma diferença central entre essas duas iniciativas: uma vez que o "Flauta Doce em Sistema" foi dedicado à apresentação e discussão de metodologias e propostas pedagógicas que se utilizam da flauta doce, o "Vida na Flauta" excluiu as temáticas essencialmente pedagógicas e abriu espaço para exposição de trabalhos nos quais a flauta doce fosse abordada a partir de pontos de vista diversos: história, performance, empreendedorismo, relação compositor-intérprete, dentre outros. Vale lembrar que os projetos foram pensados conjuntamente de modo que os eixos temáticos abordados foram acertados previamente entre os professores responsáveis. Desta maneira, evitamos redundâncias e apresentamos uma maior diversidade de assuntos concernentes à flauta doce.

Segue a lista de palestrantes e respectivas instituições de vínculo profissional, título da palestra e data de realização: David Castelo (UFG) - Flauta doce: entre a pedagogia e a performance (12/05); Profa. Sueli Helena de Miranda - Flauta doce e música popular (19/05); Prof. Pedro Hasselman Novaes - A idade média e o nascimento da flauta doce (26/05); Profa. Lucia Becker Carpena (UFRGS) - Dez anos do Prata da Casa e a importância da relação compositor-intérprete (02/06); Prof. Betiza Landim - Tecendo possibilidades com a flauta doce (09/06); Profa. Patrícia Michelini (UFRJ) - Os métodos que amamos e às vezes odiamos (16/06); Prof. Acácio Cardoso - Flautas Doces da Amazônia: uma experiência de orquestra de flautas doces no Conservatório Carlos Gomes de Belém do Pará (23/06); Profa. Daniele Cruz Barros (UFPE) - Flauta de Bloco: uma abordagem da flauta doce através da música pernambucana (30/06); Rafael Augusto e Romes Jorge - Pensando o empreendedorismo na performance da flauta doce: experiências de desenvolvimento do ENFLADU (07/07); Profa. Isamara Alves Carvalho (UFSCar) - O ensino da flauta doce em ambientes virtuais de aprendizagem e a base de conhecimento pedagógico (14/07); Prof. Antônio Chagas Neto (UFCA) - A vida na flauta em uma universidade nova: descobertas e possibilidades na UFCA (21/07). 
A escolha do título "Vida na Flauta" teve por objetivo trazer um aspecto de descontração a um projeto acadêmico implementado em um contexto de medo e ansiedade provocados pela pandemia do Coronavírus. O primeiro módulo do projeto teve início no dia 12/05/2020 e foi encerrado no dia 21/07/2020, com um total de 11 encontros. A divulgação das palestras contava com cartazes elaborados pela Assessoria de Comunicação da Escola de Música e Artes Cênicas da UFG (ASCOM - EMAC - UFG), postados em redes sociais (Instagram e Facebook) ligadas tanto à EMAC-UFG quanto ao coordenador do projeto. As postagens foram realizadas na quinta-feira que antecedia o encontro correspondente e traziam as orientações para realização das inscrições, que puderam ser feitas praticamente ao longo de todo o projeto, sendo encerradas no décimo encontro. Para efeito de inscrição, eram solicitados os seguintes dados: 1) Nome completo; 2) Instituição de vínculo (se aluno ou professor); e 3) Cidade de residência. Observava-se ainda que informações incompletas não seriam consideradas para efeito de inscrição; que estas encerravam-se às 18:00 da segunda-feira anterior ao encontro, e que aquelas solicitadas após o dia e horário limite seriam consideradas a partir do encontro subsequente. Por fim, esclarecia-se que as inscrições eram válidas para o projeto como um todo, não sendo necessário reenviá-las a cada palestra.

Dentre os objetivos do projeto, gostaria de destacar os seguintes:

- Promover maior aproximação entre flautistas profissionais e amadores.

- Incentivar maior aproximação da comunidade em geral com as Instituições Superiores de Ensino.

- Ampliar o horizonte de estudos dos alunos de música, de maneira a buscarem práticas profissionais consistentes e inovadoras.

A estrutura dos encontros foi pensada em função dos objetivos listados acima. Por essa razão, solicitei aos palestrantes que apresentassem os conteúdos em até 40 minutos, e dedicassem o restante do tempo para a discussão das questões levantadas pelos participantes. Os encontros foram então organizados com o seguinte cronograma: 
13:30 - abertura da sala virtual

14:00 - início do encontro

14:10 - início da palestra

14:40 (14:50) - final da palestra e início do debate

15:45 - encerramento do encontro

O período de meia hora compreendido entre a abertura da sala virtual e o efetivo início do encontro era utilizado principalmente para recepção dos participantes e conversas mais informais. Às 14:00, pontualmente, o encontro era oficialmente iniciado e utilizávamos os 10 primeiros minutos para avisos de rotina e apresentação do palestrante. Seguia-se a palestra que, como dito anteriormente, era feita em até 40 minutos e dava-se então início ao debate. A solicitação de falas pelos participantes deveria necessariamente ser feita por meio do chat e a palavra era aberta observando-se a ordem de inscrição. Vale destacar o clima de absoluto respeito com o qual as discussões foram realizadas!

O "Vida na Flauta" foi concebido para realização em âmbito nacional e contou com inscrições de todas as regiões do Brasil:

- Região Centro-Oeste: Distrito Federal, Goiás, Mato Grosso e Mato Grosso do Sul.

- Região Nordeste: Bahia, Ceará, Paraíba, Pernambuco, Rio Grande do Norte e Sergipe.

- Região Norte: Amapá e Pará.

- Região Sudeste: Minas Gerais, Rio de Janeiro e São Paulo.

- Região Sul: Paraná, Rio Grande do Sul e Santa Catarina. 
Ao longo da realização do projeto, fomos alegremente surpreendidos com pedidos de inscrição originários de outros países, notadamente: Alemanha, Argentina, Bélgica, Peru e Uruguai. No total, o projeto "Vida na Flauta" teve 223 inscritos, com média de 90 participantes por encontro.

\section{Conclusão}

A combinação dos três projetos, cada um com sua especificidade, revelou que é possível, desejável e eficiente o planejamento de ações conjuntas e integradas realizadas inteiramente de maneira virtual. A experiência possibilitou à universidade pública promover conteúdos de interesse social, exercendo assim seu papel fundamental na sociedade, com a vantagem de ter alcançado não apenas as comunidades vinculadas às três IFES, como também o público bastante ampliado pela divulgação espontânea dos projetos em redes sociais de grande alcance nacional e internacional.

\section{Referências}

GOHN, Daniel Marcondes. Educação musical a distância: abordagens e experiências. São Paulo: Cortez, 2011.

NUNES, Helena de Souza. Qual o papel da e-Learning no Futuro da Pós-Graduação em Música brasileira? In: XXVIII CONGRESSO DA ASSOCIAÇÃO NACIONAL DE PESQUISA E PÓSGRADUAÇÃO EM MÚSICA (ANPPOM), 2018, Manaus. Anais... Manaus: UFAM, 2018. Disponível em: https://anppom.com.br/congressos/index.php/28anppom/manaus2018/paper/viewFile/5558/204 6. Acessado em 14/11/2020.

VALENTE, José Armando. Curso de especialização em desenvolvimento de projetos com o uso das novas tecnologias: descrição e fundamentos. In: VALENTE, José Armando; PRADO, Maria Elisabete B. Brito; ALMEIDA, Maria Elizabeth Bianconcini de. Educação a Distância via internet. São Paulo: Avercamp, 2003, p. 23-55. 